\title{
Simulating Rainfall, Water Evaporation and Groundwater Flow in Three-Dimensional Satellite Images with Cellular Automata
}

\author{
Moisés Espínola ${ }^{\mathrm{a}}$, José A. Piedra-Fernández ${ }^{\mathrm{a}}$, Rosa Ayala ${ }^{\mathrm{a}}$, Luis Iribarne ${ }^{\mathrm{a}}$, \\ Saturnino Leguizamón ${ }^{\mathrm{b}}$, James Z. Wang ${ }^{\mathrm{c}}$ \\ ${ }^{a}$ Applied Computing Group, University of Almería, Spain \\ ${ }^{b}$ Regional Faculty, National Technological University, Mendoza, Argentina \\ ${ }^{c}$ The Pennsylvania State University, University Park, Pennsylvania, USA
}

\begin{abstract}
Remote sensing has been used in numerous environmental simulations with the aim of solving and improving many different kinds of problems, e.g., meteorology applications, soil quality studies, water resource exploration, and environmental protection. Besides, cellular automata have been widely used in the field of remote sensing for simulating natural phenomena over two-dimensional satellite images. However, simulations on Digital Elevation Models (DEM), or three-dimensional (3D) satellite images, are scarce. This paper presents a study of modeling and simulation of the weather phenomena of rainfall, water evaporation and groundwater flow in 3D satellite images through a new algorithm, developed by the authors, named RACA (RAinfall with Cellular Automata). The purpose of RACA is to obtain, from the simulation, numerical and 3D results related to the total cumulative flow and maximum level of water that allow us to make decisions on important issues such as analyzing how climate change will affect the water level in a particular area, estimating the future water supply of a population, establishing future construction projects and urban planning away from locations with high probability of flooding, or preventing the destruction of property and human life from future natural disasters in urban areas with probability of flooding.
\end{abstract}

Email addresses: moises.espinola@ual.es (Moisés Espínola), jpiedra@ual.es (José A. Piedra-Fernández), rmayala@ual.es (Rosa Ayala), luis.iribarne@ual.es (Luis Iribarne), sleguiza@um.edu.ar (Saturnino Leguizamón), jwang@ist.psu.edu (James Z. Wang)

Preprint submitted to Simulation Modelling Practice and Theory

June 28, 2016

(C) 2016. This manuscript version is made available under the Elsevier user license http://www.elsevier.com/open-access/userlicense/1.0/ 
Keywords: Cellular Automata, Remote Sensing, DEM Satellite Images, Water Simulation

\section{Introduction}

This paper presents research applying the methodology of cellular automata to model and simulate the meteorological phenomena of rainfall, water evaporation, and groundwater flow to Digital Elevation Model (DEM) satellite images provided by NASA, showing hydrological results in numerical and three-dimensional formats of flow remaining water. Remote sensing [31] allows us to acquire information about the surface of the land and environmental information values [5] without having actual contact with the area being observed [11]. Examples of remotely-sensed applications include searching for water resources, ascertaining soil quality, addressing environmental protection, and creating meteorology simulations, among others [20].

The weather phenomena have been extensively modeled and simulated by the worldwide scientific community. A deep investigation into the nature of these processes allows us to perceive and, above all, to predict the effects they have on the Earth's surface. Such predictions empower us to anticipate the effects of weather events in advance. For instance, at the present time we can foresee many consequences of climate change. Or, we can save lives by providing early warnings to the population before a hurricane hits.

One of the most studied and arguably the most important weather phenomenon is the process of rainfall. Its virtual modeling is a key factor in the estimation of various environmental changes caused by this phenomenon, e.g., variation of the amount of water remaining in a lake, formation of new rivers, or soil erosion process. The phenomenon of rainfall has been investigated from various scientific perspectives using diverse methods. The mathematical simulation of rainfall physical properties is a fairly complex process with many variables to consider.

Cellular automata [36] have been widely used in the last decades for environmental simulations such as modeling snow-cover dynamics [26] or snow avalanches [2], simulating land features dynamics [25] or multiple land use changes using GIS [27], modeling dynamic spatial in GIS [29], characterization of natural textures [24], modeling vegetation systems dynamics [3], detecting Vibrio cholerae by indirect measurement [28], modeling 3D clouds [23], simulating forest fire spread [21] [30], understanding modular illumination systems [4], modeling lava flows [34], understanding of urban growth 
[9] and architectural design [8], modelling of vehicular traffic [1], classifying of satellite images [7] [19], projecting population percentages infected by periodic plague [18], and simulating species competition and evolution [10].

This paper focuses on RACA (RAinfall with Cellular Automata), a new algorithm, developed by the authors, that simulates the complete rainfall process in the DEM satellite images. RACA has mainly been implemented to achieve the following four important objectives:

1. Analysis of climate change evolution in a particular geographic region. We can study the evolution of water level in a particular region as a result of climate change, taking into account various types of climates in order to consider possible alternatives in the future. Thus, we can analyze the influence of different types of climates on the total amount of accumulated water and the maximum water level reached in a particular geographic region, in order to predict future possible consequences.

2. Estimation of future water supply of a population. Taking into account the rainfall charts for the type of climate of a particular area, we can make very rough estimates of the approximate cumulative water flow in a region that has a constructed wetland. RACA also considers the initial amount of water that the lake could have (initial conditions before simulation). In addition, we can calculate the most appropriate areas for the construction of a dam to optimize the process of accumulation of water with a minimum wall built.

3. Projection of future construction projects and urban planning. We can identify safe regions for development around geographical areas at risk of flooding. Given all the graphs of rainfall recorded historically in a particular region, we can calculate the maximum height reached by the water at a given location in the $3 \mathrm{D}$ satellite image. Taking into account the results, we must avoid creating urban areas at altitudes lower than the height risk for certain areas with probability of flood in order to prevent further loss of life.

4. Natural disaster prevention in urban areas with probability of flooding. With the assistance of cellular automata, we can calculate the index ratio of flood disasters and streams in urban areas using the graphs of rainfall recorded historically in that region. In the visual results provided by the algorithm, we can clearly see which regions of the 3D satellite image will be covered by water after performing the corre- 
sponding simulations. Therefore, if an urbanized area appears to have a very high flood risk, the authorities can act to avoid future losses of life and property.

There exist several previous studies related to water process phenomenon simulation with cellular automata: a model for soil erosion by water [13], an algorithm for simulation of surface flows in large plains [32], algorithms for drainage network extraction and rainfall data assimilation [12], and developments of a flood inundation model based on the cellular automata approach [15]. All these research works obtained realistic results because they use a large number of states and rules in the cellular automata. However, they have the drawback that it is necessary to know a priori a large number of parameters to configure the performance of cellular automata, and therefore, it is necessary to perform a preliminary study of the simulation region. In many cases there is no such information to perform a simulation, or it is hard to get it in terms of time. However, RACA uses very few states and rules of cellular automata in order to simplify the simulation process, providing numerical and 3D quick view results on the final water level. Besides, RACA offers the possibility of making a preliminary field work of the study area in order to improve the basic results, adding water evaporation and groundwater flow to the simulation.

\section{Cellular Automata}

A cellular automaton is a mathematical model which consists of a set of cells usually distributed in a matrix form [22]. In recent years, cellular automata have become a powerful tool applied in remote sensing especially to implement any kind of simulation processes in satellite images. From a mathematical point of view a cellular automaton is a set of six components, as shown in the following expression:

$$
C A=(d, r, Q, \#, V, f)
$$

where:

$-d \mid d>0$ : spatial dimension of the cellular automaton. The position of each cell is shown by a vector of $Z^{d}$. Given $d=1$ it is a onedimensional cellular automaton with cells position in $Z$; given $d=2$ it is a bi-dimensional cellular automaton with cells position in $Z \times Z$; 
given $d=3$ it is a tri-dimensional cellular automaton with cells position in $Z \times Z \times Z$, and so on.

- $r$ : an index that shows the neighborhood dimension, that is, how many neighbours interact with each cell of the cellular automaton.

- Q: a set of states per cell. The set of states is finite, equal for all the cells of the cellular automaton and it can not be changed during the cellular automaton application process.

- \#: state called quiescent. This state shows inactivity in the cells of the cellular automaton and it is often used as the initial state of the cells.

- $V$ : neighborhood vector which has $r$ different elements from $Z^{d}$. The most common types of neighborhood in a cellular automaton are 4 neighbours (von Neumann neighborhood), 8 neighbours (Moore neighborhood) and 24 neighbours (extended Moore neighborhood). Figure 1 shows the most common types of neighborhood that we can find in a regular cellular automata. The neighborhood vector $V$ is a subset of $Z^{d}$, as shown in the following expression:

$$
V \subset\left(Z^{d}\right)^{r}
$$

- $f$ : cellular automaton transition function. It takes as input arguments the states of the current cell and its neighborhood, and returns a new state for the current cell. The transition function $f$ uses a set of rules that specifies the changes of the cellular automaton cell states, and it is applied to each cell through a finite number of iterations, as shown in the following expression:

$$
\begin{gathered}
f: Q^{r+1} \rightarrow Q \\
q_{i}(t)=f\left(q_{i-r}(t-1), q_{i-r+1}(t-1), \ldots, q_{i+r}(t-1)\right)
\end{gathered}
$$

where $q_{i}(t)$ is the state of the cell $i$ at time $t$. The changes in cells states of the cellular automaton occur in discrete time form. In each iteration, the whole cells stored in $Z^{d}$ are checked and the rules are applied through the transition function $f$ to each cell taking into account the neighborhood $V$ to change its state $Q$ to its corresponding state.

When we work with satellite images, we usually consider each pixel of the image as a cell of a bi-dimensional cellular automaton $(d=2)$, we normally take the Moore neighborhood $(r=8)$, we assign to each cell a defined set 


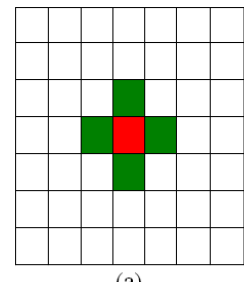

(a)

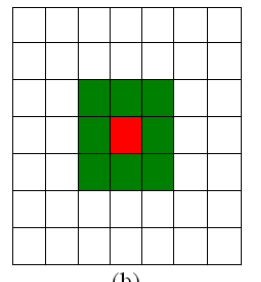

(b)

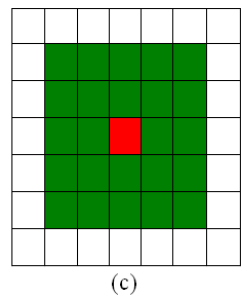

Figure 1: (a) Von Neumann neighborhood (b) Moore neighborhood (c) Extended Moore neighborhood.

of states to perform the corresponding simulation $\left(Q=q_{1}, q_{2}, \ldots, q_{n}\right)$ and we apply the different rules $\left(R=r_{1}, r_{2}, \ldots, r_{m}\right)$ in each iteration $i$ through the transition function $f$. Therefore, cellular automata have an evolution process because the cells are always changing their states through the different iterations. From this point of view, cellular automata have become a powerful tool to simulate environmental processes in satellite images.

\section{Simulating Rainfall with Cellular Automata}

This paper presents the research work of modeling and simulation of lakes and rivers flow, based on cellular automata, considering the volume of rainfall, temperature and soil type, in a given time interval. To accomplish that goal, elevation data provided by the Shuttle Radar Topographic Mission (SRTM, NASA) were used. Each pixel of the DEM satellite image corresponds to a square shaped cell with size of one square meter.

Before the simulation process, RACA loads the DEM satellite image and the initial conditions, and takes as input arguments the samples of rainfall measured in liters per square meter of different times, which may be days, weeks, months, years, etc. The configuration of the cellular automaton is also loaded before the simulation process. Then, RACA applies the rules of its cellular automaton on the DEM satellite image performing a complete simulation for each of the samples of rainfall, using as many iterations as necessary for water to fall and accumulate in the lower levels of the 3D satellite image. Each cell of cellular automaton has two states, the original altitude of the corresponding DEM pixel (state ${ }_{1}$ ) and the level reached by the water volume $\left(\right.$ state $\left._{2}\right)$. The total height of a pixel will be the sum of both states. As boundary conditions, RACA simulates a vertical wall on the borders of the image. The results are presented not only at the end 
of the whole simulation process, but also after each iteration of the cellular automaton. Therefore, RACA has the following input-output components:

- The DEM satellite image loading. state $_{1}$ of RACA is the terrain altitude obtained from the DEM satellite image. The value of this state in the cells does not vary along the simulation process.

- Initial conditions loading. Before applying the 3D simulation, RACA starts with the initial conditions: existing water level in the zone. These values are stored in state 2 of RACA and its values vary along the simulation process.

- Precipitation graphs. To carry out the simulation, the volume of precipitation must be measured in liters per square meter for each corresponding time-step (day, week, month, year, etc.).

- Temperature and permeability. RACA can take into account the air temperature and the soil permeability in order to simulate the water evaporation and the groundwater flow in the DEM satellite image. This parameters improve the simulation, and their use is optional. So, if we have field work of the study area, we can use them.

- Configuration of cellular automata. The transition function, neighborhood and maximum iterations number of RACA must be established before starting the simulation.

- RACA: rainfall with cellular automata. Each input argument (precipitation graph samples) that falls over each image pixel DEM will be used to calculate the volume of liters per square meter, and a full simulation of the water addition and outflows in the image will be established. The transition function $f$, through cellular automaton rules, will pass the corresponding volume of water from each cell to its neighbor with lower elevation height considering the total height $\left(\right.$ state $_{1}+$ state $\left._{2}\right)$, as the water goes down. When the water is reaching lower pixels that have neighboring cells with elevation greater than or equal to their own, the flow will increase on that surface: the pixel altitude $\left(\right.$ state $\left._{1}\right)$ plus volume of water level accumulated on it $\left(\right.$ state $\left._{2}\right)$. This step will be repeated in each iteration of the cellular automaton until all water of the image stagnates and stops moving between cells or until the maximum 
number of iterations. At that moment, the simulation of the current input argument ends, and the simulation of the next sample begins.

- Results. Finally, RACA shows the accumulated flow after each iteration of cellular automaton as well as the total water level after the complete process simulation. The quantity of water that exists on a given DEM image pixel is calculated by multiplying state ${ }_{2}$ of the each cell (level of water above the pixel) by 1000 because, as each DEM image pixel has a spatial resolution of $1 \mathrm{~m}^{2}$, then each three-dimensional cube of virtual representation has a resolution of $1 \mathrm{~m}^{3}$, and each cubic meter has a volume of 1000 liters. To calculate the total flow of the geographical area, RACA adds the flow stored on each of the pixels of the DEM image. This flow is shown both numerically and in 3D virtual view. Figure 2 shows the general RACA architecture with all the input-output components.

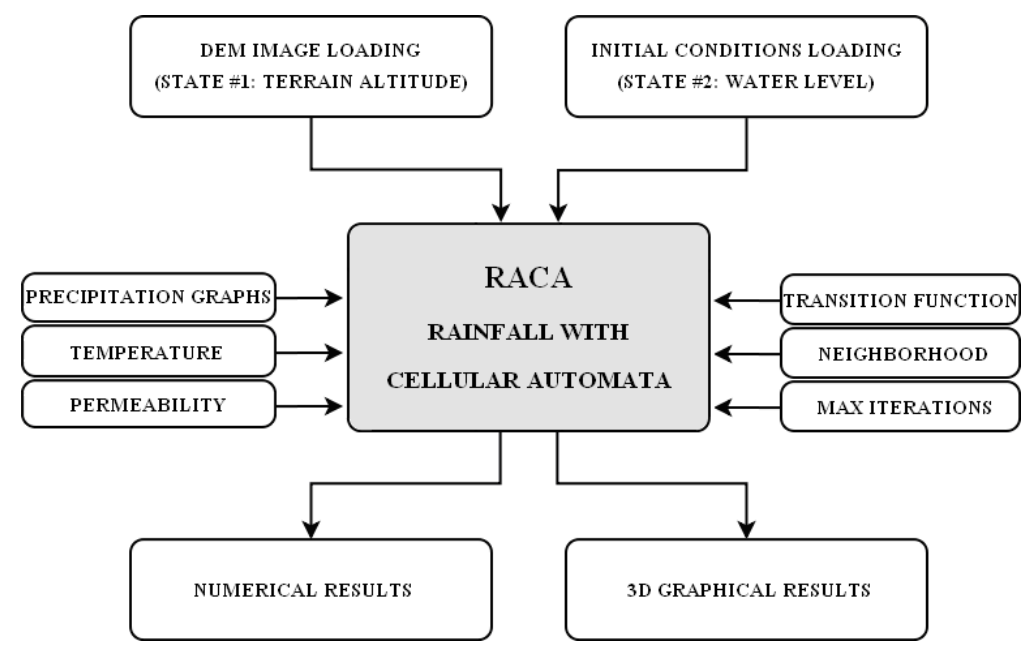

Figure 2: General RACA architecture.

The cellular automaton of RACA can be defined mathematically by the following expression:

$$
\begin{gathered}
R A C A=(d, r, Q, \#, V, f)= \\
\left(3,\{4 \mid 8\},\left[q_{\text {terrain_alt }}, q_{\text {water_level }}\right],\left[D E M \_a l t, \text { initial_water }\right], V, f\right)
\end{gathered}
$$


where:

$-d=3$ : the spatial dimension of the RACA cellular automaton is 3 , so cells are distributed in 3D form.

- $r=\{4 \mid 8\}$ : the neighborhood dimension may consist of the von Neumann or Moore neighborhood.

- $Q=\left[q_{\text {terrain_alt }}, q_{\text {water_level }}\right]$ : each cell has a set of two states, the terrain altitude and the water level.

- \# = [DEM_alt,initial_water $]$ : the quiescent state, or initial value. This value is DEM_alt for $q_{\text {terrain_alt }}$ and initial_water for $q_{w a t e r \_l e v e l}$.

- $V$ : the neighborhood vector is configurable to 4 or 8 surrounding neighbours of each one of the cells.

- $f$ : the transition function applies the rules to each one of the cells along the different iterations in order to change their states taking into account the neighborhood chosen, as shown in the following expression:

$$
f: Q^{\{4 \mid 8\}+1} \rightarrow Q
$$

The transition function applies the following rules:

- Rule \#1. If water_flow $<q_{(i) \text { water_level: }}$

$q_{(i) \text { water_level }}=q_{(i) \text { water_level }}$-water_flow

$q_{(j) \text { water_level }}=q_{(j) \text { water_level }}+$ water_flow

- Rule \#2. If water_flow $\geq q_{(i) w a t e r \_l e v e l}$ :

$$
\begin{aligned}
& q_{(i) \text { water_level }}=0 \\
& q_{(j) w a t e r \_l e v e l}=q_{(j) \text { water_level }}+q_{(i) w a t e r \_l e v e l}
\end{aligned}
$$

where $q_{(i)}$ is the current cell, $q_{(j)}$ is the neighboring cell with lower height (if there are several neighboring cells with the same height, we take a random one) and water_flow is defined by the following expression:

$$
\begin{gathered}
\text { water_flow }= \\
\frac{\left(q_{(i) t e r r a i n \_a l t}+q_{(i) \text { water_level }}\right)-\left(q_{(j) t e r r a i n \_a l t}+q_{(j) \text { water_level }}\right)}{2}
\end{gathered}
$$


RACA also uses the formulas of Visentini [33] [35] to simulate the water evaporation in lakes and rivers, based on the annual average temperature of the study area. The empirical formulas proposed by Visentini have been used in many studies [14] [16]:

$E=\left\{\begin{array}{l}75 t, \text { for water level less than } 200 \text { meters above sea level } \\ 90 t, \text { for water level between } 200 \text { and } 500 \text { meters above sea level } \\ 90 t+300, \text { for water level higher than } 500 \text { meters above sea level }\end{array}\right.$

where $E$ is the annual evaporation (in $\mathrm{mm}$ ) and $t$ is the annual average temperature in degrees Celsius.

Finally, RACA uses the soil permeability coefficient with the aim of estimating the hydraulic conductivity and simulate the groundwater flow, which is specific to the material through the water is flowing. Table 1 shows the typical ranges of permeability coefficient for different types of soil [6] [17].

\begin{tabular}{|l|c|}
\hline Type of soil & Permeability $k\left(\mathrm{~cm}^{2}\right)$ \\
\hline Well sorted gravel & $10^{-3} / 10^{-4}$ \\
\hline Highly fractured rocks & $10^{-3} / 10^{-6}$ \\
\hline Sand and gravel & $10^{-5} / 10^{-7}$ \\
\hline Peat & $10^{-7} / 10^{-8}$ \\
\hline Oil reservoir rocks & $10^{-7} / 10^{-9}$ \\
\hline Very fine sand & $10^{-8} / 10^{-11}$ \\
\hline Layered clay & $10^{-9} / 10^{-11}$ \\
\hline Fresh sandstone & $10^{-10} / 10^{-11}$ \\
\hline Fresh limestone or dolomite & $10^{-12} / 10^{-13}$ \\
\hline Unweathered clay & $10^{-12} / 10^{-15}$ \\
\hline Fresh granite & $10^{-14} / 10^{-15}$ \\
\hline
\end{tabular}

Table 1: Permeability coefficients for different types of soil.

Figure 3 shows the water evaporation and groundwater flow processes that RACA has into account in order to simulate the decreasing of water level.

\section{Experimental Features}

The DEM satellite images, provided by SRTM (NASA), correspond to two regions in Almería and Granada, southeast Spain: Sierra Nevada, a cold zone, with the geographical coordinates North $37^{\circ}$ and West $3.5^{\circ}$, and the Tabernas Desert, an arid desert, with the geographical coordinates North $37^{\circ}$ and West $2.5^{\circ}$, as shown in Figure 4 (a)(b). 


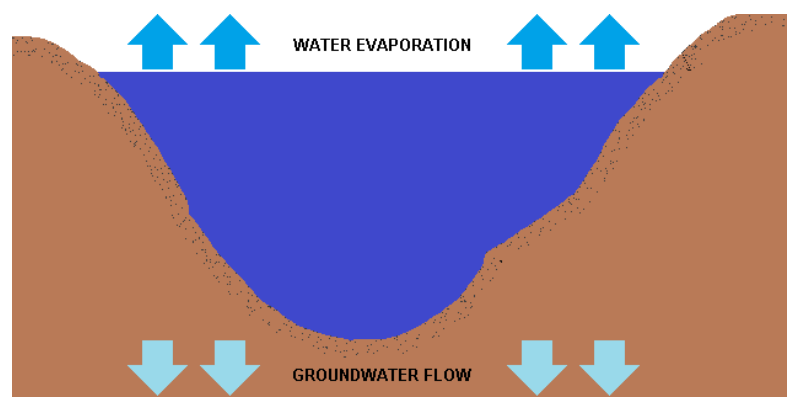

Figure 3: Water evaporation and groundwater flow.

The original DEM images were corrected from some voids appearing on it and improved in spatial resolution through resampling and interpolation

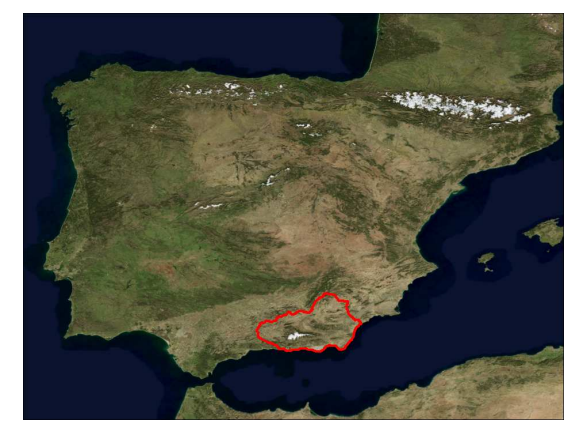

(a)
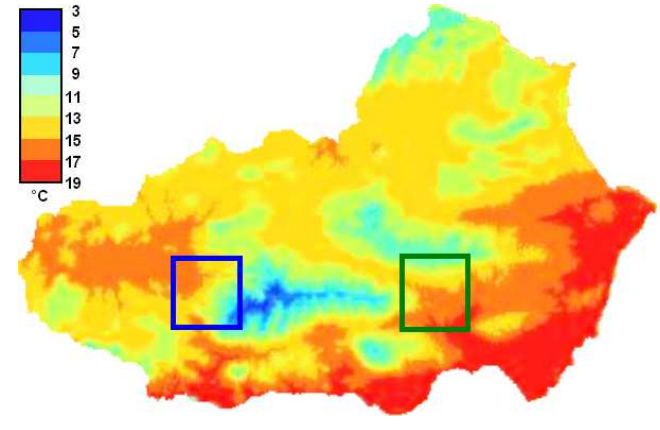

(c)

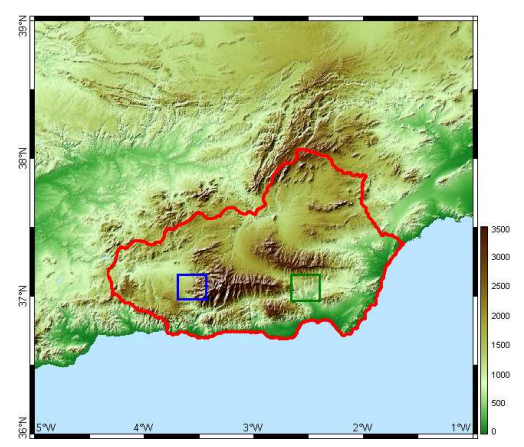

(b)

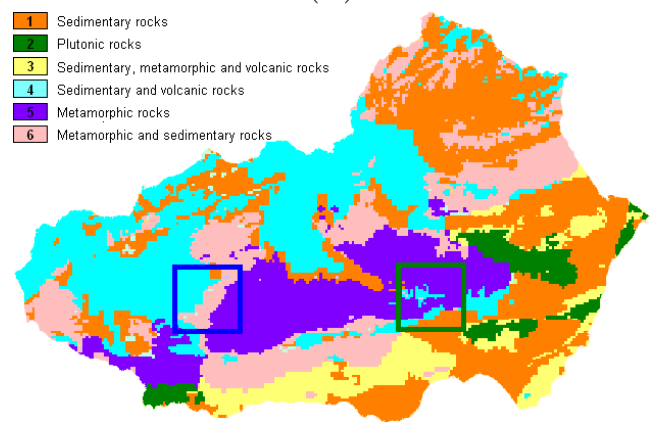

(d)

Figure 4: Experimental features of the DEM satellite images: (a) Almería and Granada provinces, situated in southeast Spain; (b) Sierra Nevada (blue square), the Tabernas Desert (green); (c) temperature areas; (d) soil areas. 
techniques. Each new DEM image has $1200 \times 1200$ pixels, each pixel has a spatial resolution of $1 \mathrm{~m}^{2}$, with an altitude ranging from 236 to $3482 \mathrm{~m}$ in Sierra Nevada, and ranging from 213 to $2602 \mathrm{~m}$ in the Tabernas Desert. Temperature and soil in southeast Spain are extremely diverse. Figure 4 (c) shows the temperature areas in Almería and Granada with the study areas marked by the squares, and Figure $4(\mathrm{~d})$ shows the six soil areas. The permeability coefficient has been estimated for each area: $1\left(10^{-13}\right), 2\left(10^{-15}\right)$, $3\left(10^{-12}\right), 4\left(10^{-14}\right), 5\left(10^{-10}\right)$ and $6\left(10^{-11}\right)$, having into account the rock type composition of the soil. Specifically, Sierra Nevada is characterized by soil areas 1, 4, 5 and 6, and the Tabernas Desert is characterized by soil areas 1,4 and 5 .

In order to compare the results provided by different types of climate, the rainfall simulations with RACA have been carried out using four different annual precipitation graphs (annual mean precipitation of last 30 years), each one corresponding to a different climate of Spain: sub-desert climate, continental climate, Mediterranean climate and oceanic climate (source AEMET). Figure 5 shows the graphs of annual precipitation for the four different types of climates. As can be seen, the annual precipitation graphs are arranged in growing order, taking as reference the total number of liters per square meter per year. The first graph corresponds to the drier climate and the last graph corresponds to the wetter climate in which precipitation is recorded during all months of the year.

For each graph of annual precipitation, 12 simulations have been made, one for each month of the year. Therefore, the results of each DEM satellite image were obtained after making a total of 48 simulations. For each simulation, RACA used as many iterations of cellular automata as necessary until the water stopped moving. In the first few months, in which water levels are lower, the number of iterations of the cellular automata has been greater than in the subsequent months in which water levels are higher, consequently the water has less height to descend the mountain in those early months. To simplify the large number of results offered by all the simulations, we used as a reference only the annual final result of each type of climate after the simulation of all the months of the year.

\section{Experiments and Results}

RACA can be configured to ignore or take into account the water evaporation and groundwater flow processes. In this paper, we performed ex- 
periments of both types in order to compare those results, and thus analyze the amount of water lost through water evaporation and groundwater flow processes.

In the first simulation, the sub-desert climate records a total annual precipitation of 199 liters per square meter. The total cumulative flow in this type of climate is 286 million liters. With that amount of annual rainfall, RACA calculates the water level accumulated at the lower areas, flowing from the higher zones. The water reaches a maximum height level of 282 meters above sea level in Sierra Nevada and 265 meters above sea level in the Tabernas Desert.

In the second simulation, the continental climate records a total annual precipitation of 427 liters per square meter. The total cumulative flow is 614 million liters, with the water reaching a maximum height of 298 meters above sea level in Sierra Nevada and 297 meters above sea level in the Tabernas Desert.

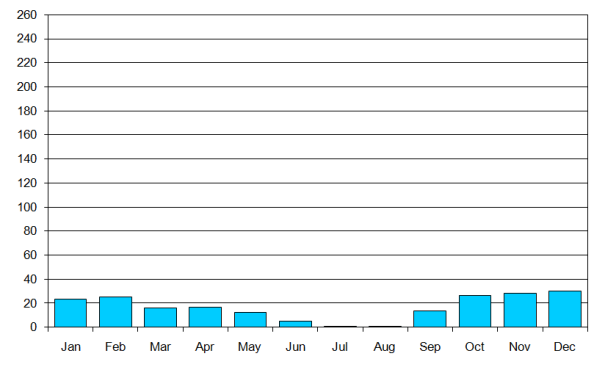

(a)

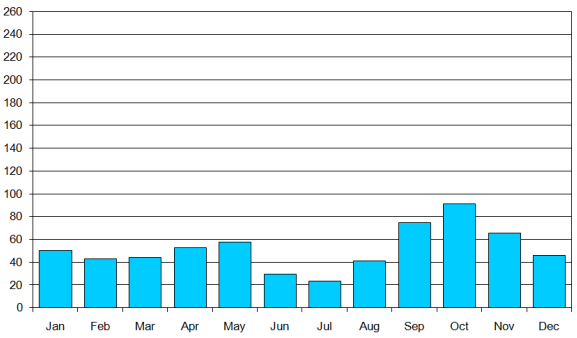

(c)

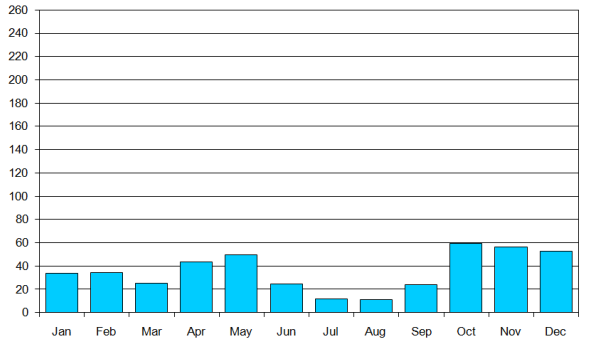

(b)

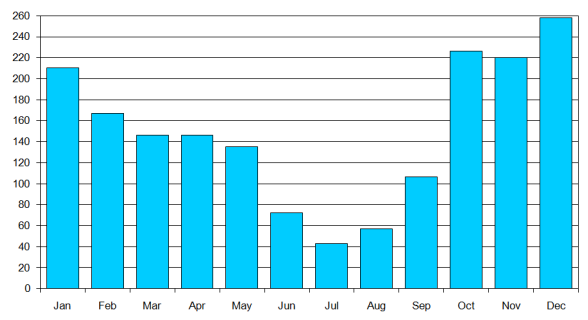

(d)

Figure 5: Graphs of annual precipitation, measured in liters per square meter, for four types of climate in Spain: (a) sub-desert climate, (b) continental climate, (c) Mediterranean climate, and (d) oceanic climate. 
In the third simulation, the Mediterranean climate records a total annual precipitation of 621 liters per square meter. The total cumulative flow is 893 million liters, reaching a maximum water level height of 308 meters above sea level in Sierra Nevada and 316 meters above sea level in the Tabernas Desert.

Finally, the oceanic climate records a total annual precipitation of 1787 liters per square meter. The cumulative flow is 2571 million liters, reaching the maximum water level height of 345 meters above sea level in Sierra Nevada and 379 meters above sea level in the Tabernas Desert. Table 2 shows a summary of the numerical annual results obtained after conducting simulations of the four climate types in the Sierra Nevada and the Tabernas Desert.

\begin{tabular}{|l|c|c|c|c|}
\hline Type of weather & ATP & TCF & MLW1 & MLW2 \\
\hline (a) Sub-desert climate & 199 liters $/ \mathrm{m}^{2}$ & $286 \times 10^{6}$ liters & $282 \mathrm{~m}$ & $265 \mathrm{~m}$ \\
\hline (b) Continental climate & 427 liters $/ \mathrm{m}^{2}$ & $614 \times 10^{6}$ liters & $298 \mathrm{~m}$ & $297 \mathrm{~m}$ \\
\hline (c) Mediterranean climate & 621 liters $/ \mathrm{m}^{2}$ & $893 \times 10^{6}$ liters & $308 \mathrm{~m}$ & $316 \mathrm{~m}$ \\
\hline (d) Oceanic climate & 1787 liters $/ \mathrm{m}^{2}$ & $2571 \times 10^{6}$ liters & $345 \mathrm{~m}$ & $379 \mathrm{~m}$ \\
\hline
\end{tabular}

Table 2: Numerical results obtained in the four types of weather (where ATP=Annual Total Precipitation, TCF=Total Cumulative Flow, MLW1=Maximum Level of Water in Sierra Nevada and MLW2=Maximum Level of Water in the Tabernas Desert).

After performing the simulations taking into account the water evaporation and groundwater flow processes, the water disappears in the simulations of all the climates, except in the last one: oceanic climate. In this case, the total cumulative flow in Sierra Nevada is 618 million liters, reaching a maximum water level height of 299 meters above sea level, and the total cumulative flow in the Tabernas Desert is 64 million liters, reaching a maximum water level height of 234 meters above sea level. The total cumulative flow of Sierra Nevada and the Tabernas Desert changes because the temperature and soils are different in these two regions.

Figure 6 shows the 3D graphic results obtained in Sierra Nevada and Figure 7 in the Tabernas Desert, without having into account the water evaporation and groundwater flow processes. Figure 8 shows the 3D graphic results obtained in Sierra Nevada and the Tabernas Desert in oceanic climate, having into account the water evaporation and groundwater flow processes.

In the 3D satellite images, the water is represented by dark blue, the lower areas with light colors (blue or light green), and the higher areas with 


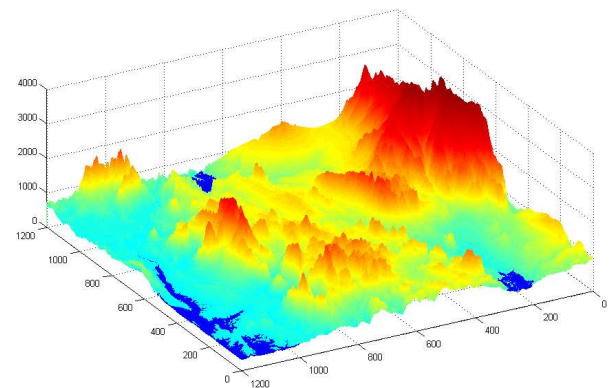

(a)

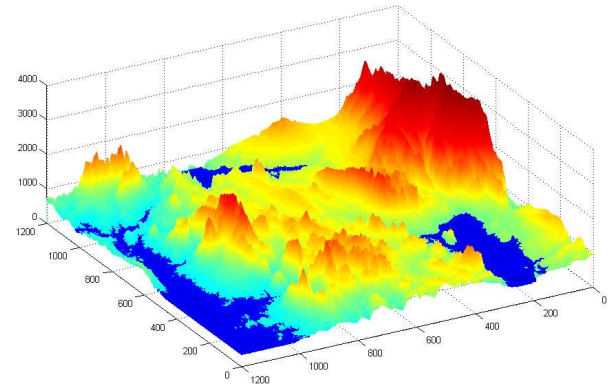

(c)

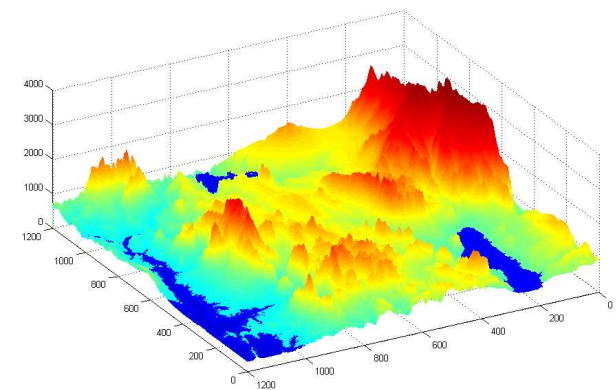

(b)

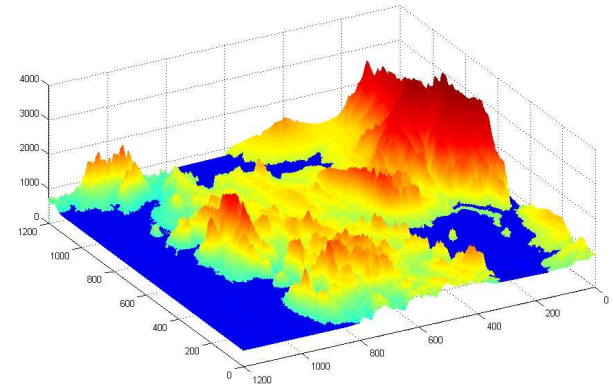

(d)

Figure 6: Graphic results obtained in Sierra Nevada: (a) sub-desert climate, (b) continental climate, (c) Mediterranean climate, and (d) oceanic climate. 


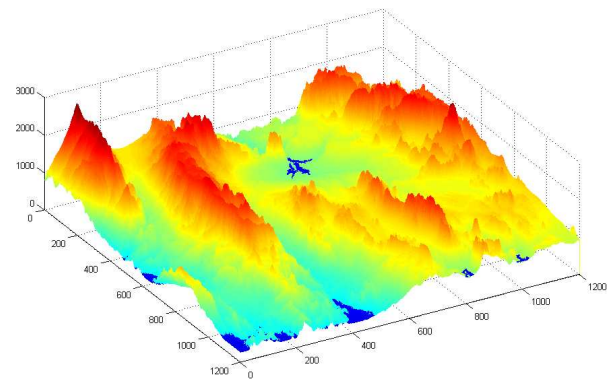

(a)

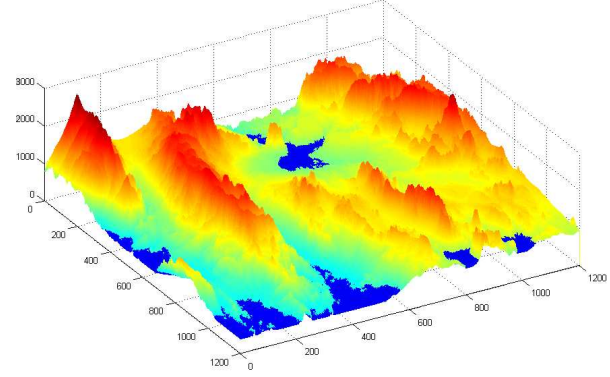

(c)

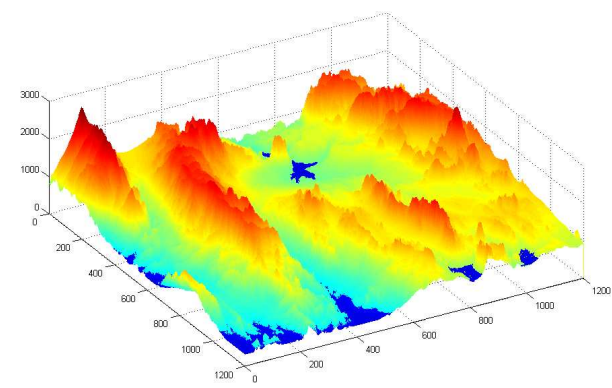

(b)

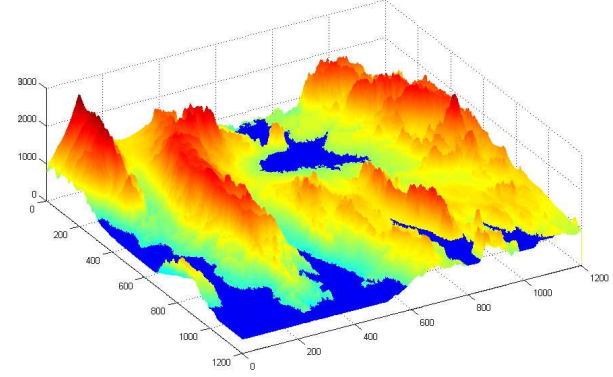

(d)

Figure 7: Graphic results obtained in the Tabernas Desert: (a) sub-desert climate, (b) continental climate, (c) Mediterranean climate, and (d) oceanic climate.

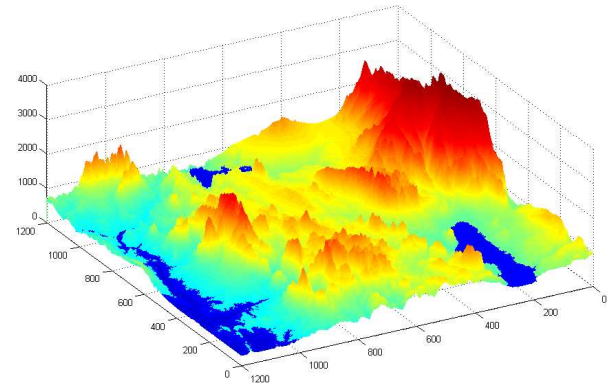

(a)

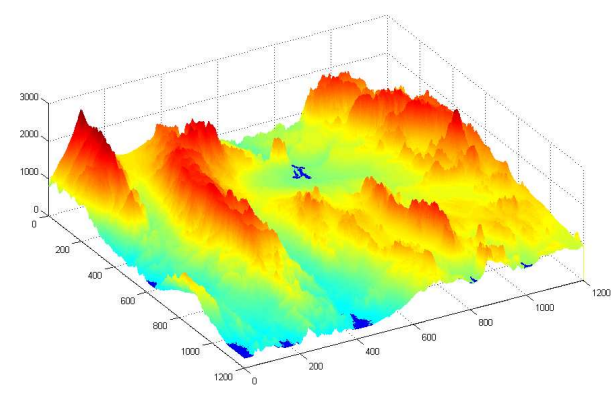

(b)

Figure 8: Graphic results having into account the water evaporation and groundwater flow processes in oceanic climate: (a) Sierra Nevada, and (b) The Tabernas Desert. 
darker colors (like orange or dark red). These 3D graphic results can be configured to provide the best possible view by changing the position of the camera through the keyboard, not only to view the image from the desired perspective but also to navigate freely across the surface of the DEM satellite image with the objective of seeing the most interesting details up close. This technique offers a multitude of practical applications, such as checking the flood risk in villages near wetlands depending on the amount of rainfall in a year in that geographic region.

The results obtained by RACA enable us to classify the pixels of the DEM image into three distinct regions: no water, flooded and flood risk. The number of pixels without water and flooded can be obtained directly through the results provided by RACA.

The most interesting pixels are those that are at risk of flooding and therefore the pixels that are very close in distance and height to the flooded areas of the DEM image. To calculate the number of pixels at risk of flooding we have established a range of risk of 2 meters above the water level in the flooded areas, so that all pixels that are in this range are at risk of flooding, for being very close to already flooded areas. The amount of flood risk pixels are subtracted from pixels without water.

Figure 9 shows a graph with the percentage of pixels without water, flood and flood risk in Sierra Nevada DEM image for the 4 types of weather. As can be seen, by increasing the total amount of flooded DEM image pixels, it also increases the number of pixels at risk of flooding in the image $(0.4 \%$ for the sub-desert climate, $1.3 \%$ for the continental climate, $1.7 \%$ for the Mediterranean climate and $2.9 \%$ for the oceanic climate).

Figure 10 shows a graph with the percentage of pixels without water, flood and flood risk in the Tabernas Desert DEM image for the 4 types of weather. Although the values of the percentages are similar to those of the image of Sierra Nevada, there are some differences because both images have different terrain, which causes that there is a lower percentage of flooded pixels in the Tabernas Desert image and consequently a lower percentage of pixels at risk of flooding $(0.3 \%$ for the sub-desert climate, $1.1 \%$ for the continental climate, $1.5 \%$ for the Mediterranean climate and $2.4 \%$ for the oceanic climate). 


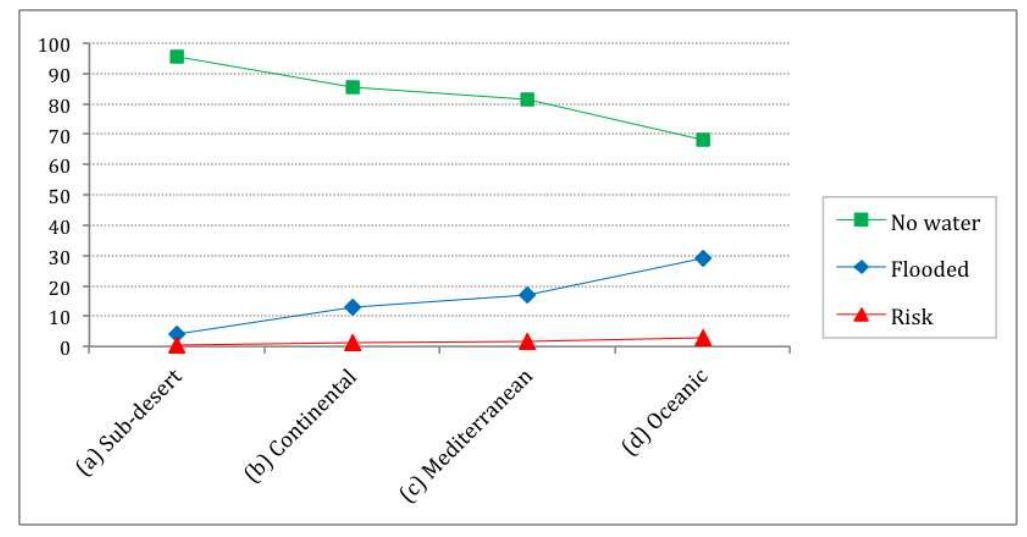

Figure 9: Percentage of pixels without water, flood and flood risk in Sierra Nevada for the 4 types of weather.

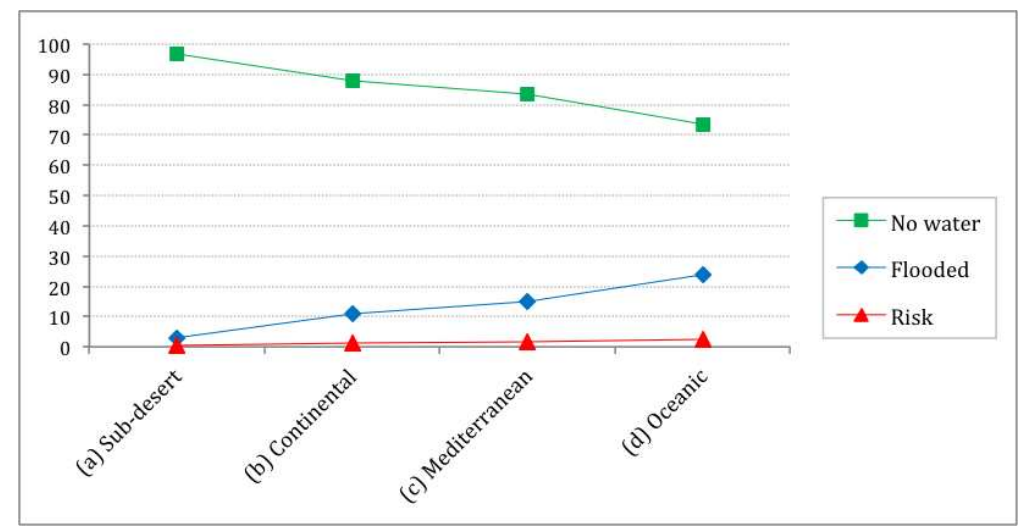

Figure 10: Percentage of pixels without water, flood and flood risk in The Tabernas Desert for the 4 types of weather.

\section{Conclusions}

RACA is a new algorithm, based on cellular automata, that models and simulates the weather phenomena of rainfall, water evaporation and groundwater flow in 3D satellite images. Although cellular automata have been widely used in the field of remote sensing for simulating natural phenomena over two-dimensional satellite images, there are hardly any studies on three-dimensional ones.

In this paper, RACA has been used as a tool for analysis of climate change and evolution in two given regions: Sierra Nevada and the Tabernas 
Desert, using in both DEM satellite images the graphs of different climates in order to study how the amount of water would change depending on each particular climate, considering several possible future alternatives (objective $\# 1$ ).

On the one hand, the purpose of RACA is to obtain, from the simulation, numerical and 3D results related to the water level that allow us to make decisions on important issues, classifying the pixels of the DEM image into three distinct regions: no water, flooded and flood risk. Flooded pixels allow us to target objective \#2 of RACA: determining the supply of water from a population. This value is indicated by TCF (Total Cumulative Flow) obtained after the rainfall, water evaporation and groundwater flow simulation, and specifies the total amount of accumulated water in the DEM satellite image.

On the other hand, MLW (Maximum Level of Water) in the DEM image determines the risk zones. Pixels at risk of flooding will allow us to achieve the objectives \#3 and \#4 of RACA: projection of future construction projects, and natural disaster prevention in urban areas with a probability of flooding. Thus, if we are planning future urban construction projects, we should avoid these areas at risk of flooding (objective \#3). Furthermore, if there is currently any urban area over pixels at risk of flooding, it would be advisable to establish the appropriate security measures to prevent that future disasters cause loss of human lives (objective \#4).

Therefore, all information provided by RACA is useful for environmental management of natural and urban terrains, to analyze how climate change could affect the water level in a particular area, to estimate the water supply of a village, to appropriate planning urban construction projects and to avoid flooding and loss of human lives.

With regard to future work, simulation opportunities of cellular automata are diverse and pragmatic in 3D satellite images. For example, cellular automata could be used to simulate the process of soil erosion after the fall of rain for a long period of time to see how the passage of water modifies the appearance of the landscape.

\section{Acknowledgments}

This work was funded by the EU ERDF and the Spanish Ministry of Economy and Competitiveness (MINECO) under Project TIN2013-41576-R, and the Andalusian Regional Government (Spain) under Project P10-TIC-6114. 
This work was also supported by the CEiA3 and CEIMAR consortiums. J. Z. Wang has been funded by the National Science Foundation under Grant No. 1027854.

\section{References}

[1] Aponte A and Moreno JA (2006) "Cellular automata and its application to the modelling of vehicular traffic in the city of Caracas", ACRI 2006, LNCS 4173: 502-511.

[2] Avolio MV, Errera A, Lupiano V, Mazzanti P and Di Gregorio S (2010) "Development and calibration of a preliminary cellular automata model for snow avalanches", ACRI 2010, LNCS 6350: 83-94.

[3] Balzter H, Braun P and Kühler W (1998) "Cellular automata models for vegetation dynamics", Ecological Modelling, 107: 113-125.

[4] Bandini S, Bonomi A and Vizzari G (2010) "A cellular automata based modular illumination system", ACRI 2010, LNCS 6350: 334-344.

[5] Barret EC and Curtis LF (1999) "Introduction to environmental remote sensing", Cheltenham Stanley Thornes Publishers Ltd.

[6] Bear J (1972) "Dynamics of fluids in porous media", Courier Corporation, Dover.

[7] Bi Y, Zhang Y and Chen Y (2006) "Image classification method based on cellular automata transforms", WCICA 2006, 10058-10062.

[8] Castro A and Gómez N (2008) "Self-organizing map and cellular automata combined technique for advanced mesh generation in urban and architectural design", International Journal of Information Technologies and Knowledge, 2: 354-360.

[9] Cheng J and Masser I (2002) "Cellular automata based temporal process understanding of urban growth", ACRI 2002, LNCS 2493: 325-336.

[10] Chopard B and Lagrava D (2006) "A cellular automata model for species competition and evolution", ACRI 2006, LNCS 4173: 277-286.

[11] Chuvieco E and Huete A (2010) "Fundamentals of satellite remote sensing", CRC Press. 
[12] Coppola E, Tomassetti B, Mariotti L, Verdecchia M and Visconti G (2007) "Cellular automata algorithms for drainage network extraction and rainfall data assimilation", Hydrological Sciences-Journal-des Sciences Hydrologiques, 52(3): 579-592.

[13] D' Ambrosio D, Di Gregorio S, Gabriele S and Gaudio R (2001) "A cellular automata model for soil erosion by water", Physics and Chemistry of the Earth (B), 26(1): 33-39.

[14] Di Matteo L, Dragoni W, Pierucci L and Valigi D (2006) "Studio idrogeologico e climatico del bacino del lago di Montedoglio (F. Tevere, Arezzo Italia Centrale)", Giornale di Geologia Applicata 3, 32-38.

[15] Dottori F and Todini E (2011) "Developments of a flood inundation model based on the cellular automata approach: testing different methods to improve model performance", Physics and Chemistry of the Earth $36,266-280$.

[16] Dragoni W and Valigi D (1994) "Contributo alla stima dell'evaporazione dalle superfici liguide nell’Italia Centrale", Geologica Romana 30, 151158.

[17] Dysli M, Steiner W and Fontana A (2013) "Correlations in soil mechanics", Presses polytechniques et universitaires romandes.

[18] Dzwinel W (2004) "A cellular automata model of population infected by periodic plague", ACRI 2004, LNCS 3305: 464-473.

[19] Espínola M, Piedra-Fernández JA, Ayala R, Iribarne L and Wang JZ (2015) "Contextual and hierarchical classification of satellite images based on cellular automata," IEEE Transactions on Geoscience and Remote Sensing, 53(2): 795-809.

[20] Guzman OF and Gómez ID (2007) "Fundamentos físicos de teledetección", Instituto Geográfico Agustin Codazzi IGAC.

[21] Karafyllidis I and Thanailakis A (1997) "A model for predicting forest fire spreading using cellular automata", Ecological Modelling, 99: 87-97.

[22] Kari J (2005) "Theory of cellular automata: a survey", Theoretical Computer Science, 334: 3-33. 
[23] Kowsuwan N and Kanongchaiyos P (2009) "3D cloud animation using CA based method", ISPACS 2009, 387-392.

[24] Leguizamón S, Espínola M, Ayala R, Iribarne L and Menenti M (2010) "Characterization of texture in images by using a cellular automata approach", CCIS 112(2): 522-533.

[25] Leguizamón S (2006) "Modelling land features dynamics by using cellular automata techniques", Proceedings of the ISPR Technical Comission 7 Mid-Term Symposium "From pixels to Processes", 497-501.

[26] Leguizamón S (2005) "Simulation of snow-cover dynamics using the cellular automata approach", Proc.of the 8th Int. Symposium on High Mountain Remote Sensing Cartography, 87-91.

[27] Li X and Gar-on Yeh A (2002) "Neural-network-based cellular automata for simulating multiple land use changes using GIS", International Journal of Geographical Information Science, 16(4): 323-343.

[28] Lobitz B, Beck L, Huq A, Woods B, Fuchs G, Faruque A and Colwell R (2000) "Climate and infectious disease: use of remote sensing for detection of Vibrio cholerae by indirect measurement", Proc. National Academic Sci. USA, 97(4): 1438-43.

[29] Mahajan Y and Venkatachalam P (2009) "Neural network based cellular automata model for dynamic spatial modeling in GIS", ICCSA 2009, LNCS 5592: 341-352.

[30] Muzy A, Innocenti E, Aiello A, Santucci JF, Santonio PA and Hill D (2005) "Modelling and simulation of ecological propagation processes: application to fire spread", Environmental Modelling and Software, 20: 827-842.

[31] Rees WG (2001) "Physical principles of remote sensing", Cambridge University Press 2nd Edition.

[32] Rinaldi P, Dalponte D, Vénere M and Clausse A (2007) "Cellular automata algorithm for simulation of surface flows in large plains", Simulation Modelling Practice and Theory 15, 315-327. 
[33] Romita PL (1953) "Contributo alla previsione dell'evaporazione dalle grandi superfici liquide", L'Acqua, 31: 9-10.

[34] Spataro W, D Ambrosio D, Rongo R and Trunfio GA (2004) "An evolutionary approach for modelling lava flows through cellular automata", ACRI 2004, LNCS 3305: 725-734.

[35] Visentini M (1937) "L'evapotraspirazione dagli specchi liquidi", Memorie e Studi Idrografici, Pubblicazione n. 2 del Servizio Idrografico, Ist. Poligrafico dello Stato, 9, Roma.

[36] Wolfram S (2002) "A new kind of science", Wolfram Media Inc. 